\title{
Implementasi Algoritma FP-Growth Untuk Menemukan Pola Frekuensi Pembelian Lauk Pada Rumah Makan Takana Juo
}

\author{
Dewi Eka Putri*, Eka Praja Wiyata Mandala \\ Fakultas Ilmu Komputer, Prodi Teknik Informatika, Universitas Putra Indonesia YPTK Padang, Padang, Indonesia \\ Email : 1,*dewieka@upiyptk.ac.id, 2ekaprajawm@upiyptk.ac.id \\ Email Penulis Korespondensi: dewieka@upiyptk.ac.id
}

\begin{abstract}
Abstrak-Semua masakan yang berasal dari Sumatera Barat lebih populer disebut dengan masakan Padang. Masakan padang merupakan salah satu masakan yang paling disukai oleh masyarakat Indonesia maupun wisatawan luar negeri. Rumah makan yang menyajikan masakan padang, tersebar di seluruh wilayah Indonesia. Salah satunya adalah Rumah Makan Takana Juo yang terletak di Singkawang Kalimantan Barat. Rumah makan ini menyajikan berbagai macam lauk dengan cita rasa yang khas dari Sumatera Barat. Masalah yang terjadi pada rumah makan ini adalah rumah makan ini sering kehabisan beberapa jenis lauk, sementara lauk yang lain masih banyak, sehingga sering banyak lauk tersisi setiap harinya. Jadi, diperlukan solusi untuk melihat pola beli pelanggan dari rumah makan dalam membeli lauk, sehingga rumah makan dapat mengatur lauk yang akan dijual setiap harinya. Pendekatan dengan data mining dinilai cocok untuk menemukan pola beli pelanggan ini. Penelitian ini menggunakan data transaksi penjualan lauk dalam satu hari sebagai data sampel sebanyak 12 transaksi. Contoh dari pola beli yang dihasilkan adalah dari 12 transaksi yang membeli ayam bakar, 6 transaksi membeli rendang daging. Algoritma yang digunakan untuk membantu rumah makan dalam menemukan pola beli pelanggan adalah Algoritma FP-Growth, sehingga dapat membantu rumah makan dalam mengatur jumlah lauk yang akan dijual setiap harinya. Hasil dari penelitian ini adalah keputusan dalam pengadaan lauk di rumah makan yang dapat dilihat dari pola frekuensi pembelian lauk yang dilakukan oleh pelanggan.
\end{abstract}

Kata Kunci: Pola Frekuensi; Pembelian; Data Mining; FP-Growth; Rumah Makan; Masakan Padang

Abstract-All dishes originating from West Sumatra are more popularly known as Padang cuisine. Padang cuisine is one of the most preferred dishes by Indonesians and foreign tourists. Restaurants that serve Padang cuisine, spread all over Indonesia. One of them is the Takana Juo Restaurant located in Singkawang, West Kalimantan. This restaurant serves a variety of side dishes with a distinctive taste from West Sumatra. The problem that occurs in this restaurant is that this restaurant often runs out of several types of side dishes, while there are still many other side dishes, so that many side dishes are often left out every day. So, a solution is needed to see the buying patterns of customers from restaurants in buying side dishes, so that the restaurant can arrange the side dishes that will be sold every day. The data mining approach is considered suitable for finding these customer buying patterns. This study uses data on side dishes sales in one day as a sample data of 12 transactions. Examples of the resulting buying patterns are 12 transactions that buy grilled chicken, 6 transactions buy beef rendang. The algorithm used to help restaurants find customer buying patterns is the FP-Growth Algorithm, so it can help restaurants regulate the number of side dishes to be sold each day. The result of this research is the decision in the procurement of side dishes at the restaurant which can be seen from the frequency pattern of side dishes purchases made by customers.

Keywords: Frequent Pattern; Purchases; Data Mining; FP-Growth; Restaurant; Padang Cuisine

\section{PENDAHULUAN}

Masakan Padang adalah salah satu kuliner yang memiliki cita rasa khas asli dari Indonesia. Masakan Padang banyak sekali penggemarnya, sehingga banyak orang asli Sumatera Barat yang pergi merantau untuk membuka dan menjalankan bisnis masakan padang [1]. Masakan Padang menjadi tumpuan kuliner yang dimiliki oleh kota Padang sehingga bisa terkenal di Indonesia bahkan sampai ke luar negeri, yang dibuktikan dengan adanya Rumah Makan Padang yang banyak terdapat di seluruh kota besar di Indonesia [2]. Masakan Padang merupakan salah satu jenis makanan etnis yang mempunyai cita rasa khas dan banyak digemari. Sehingga, tidak heran jika menjadi salah satu rumah makan etnis terluas yang tersebar di seluruh penjuru Indonesia [3].

Rumah Makan Padang adalah rumah makan etnis di Indonesia yang berasal dari Minangkabau yang telah sangat dikenal di wilayah Indonesia dan di beberapa negara tetangga yang memiliki etnis Melayu. Berbeda dengan rumah makan pada umumnya, di rumah makan Padang akan dihidangkan seluruh lauk yang tersedia dengan piring kecil. Sehingga pelanggan bisa mengambil secara langsung lauk yang diinginkan [4].

Karena pada umumnya lauk masakan Padang dihidangkan semua diatas meja, maka pelanggan yang datang biasanya tidak sendiri namun datang secara berkelompok, misalnya satu keluarga yang makan bersama, pasti memilih lauk yang berbeda-beda, sehingga lauk yang dipilih oleh pelanggan tidak bisa diprediksi, maka akan terjadi masalah yaitu adanya lauk yang lebih cepat habis dan ada lauk yang tersisa setiap harinya. Masalah ini juga dihadapi oleh Rumah Makan Takana Juo yang didirikan oleh seorang perantau dari daerah Padang Panjang. Rumah Makan ini sudah berdiri dari tahun 1998 di Kota Singkawang, Kalimantan Barat.

Penelitian ini dilakukan untuk dapat menemukan pola beli lauk yang dibeli oleh pelanggan di Rumah Makan Takana Juo. Data yang digunakan pada penelitian ini adalah data transaksi dari penjualan lauk yang dibeli oleh pelanggan. Data penjualan akan dianalisis untuk mengetahui tingkat kecenderungan konsumen terhadap produk yang akan dibeli, sehingga akan diperoleh suatu pola beli konsumen terhadap produk tersebut [5]. Pola frekuensi merupakan item di dalam basis data yang memiliki batas tertentu atau biasa disebut juga dengan minimum support [6]. Lauk masakan padang yang dibahas pada penelitian ini adalah lauk yang umum tersedia di rumah makan padang. Lauk yang sering disajikan diantaranya adalah ayam bakar, ayam lado hijau, ayam pop, 
gulang cancang, dendeng batokok lado hijau, randang, itiak lado hijau, pangek padeh, dendeng lambok, palai bada, kalio dagiang, gulai tunjang, gulai usus, gulai paku dan masih banyak lagi [7][8].

Pendekatan yang dilakukan pada penelitian ini adalah data mining. Data mining merupakan suatu proses yang dilakukan untuk memperoleh nilai tambah dari suatu data sehingga bisa menghasilkan sebuah pengetahuan yang dapat digunakan untuk pengambilan keputusan [9]. Data mining merupakan proses yang memakai berbagai teknik dan alat analisis data agar menemukan hubungan dan pola yang tersembunyi [6]. Metode yang digunakan adalah Association Rule, yang merupakan salah satu teknik yang ada dalam data mining untuk menemukan aturan assosiatif antara kombinasi item [10]. Sementara algoritma yang digunakan pada penelitian ini adalah Algoritma FP-Growth, yang merupakan salah satu bentuk peneyelesaian dari metode asosiasi, dimana FP-Growth merupakan pengembangan dari Apriori [11]. Algoritma FP-Growth menentukan kombinasi data yang sering muncul (frequent itemset) dalam kumpulan data. Algoritma FP-Growth akan membangkitkan struktur data Tree atau disebut juga dengan Frequent Pattern Tree (FP-Tree) [12]. Algoritma FP-Growth adalah salah satu alternatif yang dapat dipakai untuk menentukan himpunan data yang paling sering muncul (frequent itemset) dalam suatu kumpulan data [13].

Pada penelitian [14], permasalahan yang dihadapi adalah masalah layout atau tata letak dari lauk yang dijual di Rumah Makan Murah Meriah. Untuk mengatasi masalah tersebut, dilakukan pendekatan dengan menggunakan data mining yang menggunakan algoritma Apriori. Penelitian ini menghasilkan sebuah aplikasi yang dapat melakukan penyusunan layout untuk menempatkan lauk dari Rumah Makan Murah Meriah. Penelitian berikutnya [15], membahas permasalahan yang terjadi di Waroeng Spesial Sambal. Masalah yang dihadapi adalah kurangnya antisipasi terhadap persediaan menu ataupun bahan baku yang harus disediakan oleh Waroeng Spesial Sambal, hal ini mengakibatkan berkurangnya pelanggan yang datang. Penelitian ini menghasilkan sebuah aplikasi data mining dengan menggunakan algoritma Apriori. Berbeda dengan penelitian diatas, penelitian [16] membahas masalah penyusunan menu makanan prasmanan pada rumah makan Asgar Sukabumi. Penyajian prasmanan cenderung menyulitkan pelanggan saat akan mengambil makanan yang satu dengan yang lain, masalah akan bertambah besar jika sedang banyak pelanggan yang makan di rumah makan tersebut. Untuk mengatasi masalah tersebut, perlu dibuatkan pola beli pelanggan, agar bisa menyusun menu makanan sesuai dengan kebiasaan yang dilakukan oleh pelanggan. Penelitian ini juga menggunakan algoritma Apriori. Penelitian yang dilakukan sebelumnya, sebagian besar menggunakan aturan asosiasi yang sama, tetapi menggunakan algoritma yang berbeda, yaitu Algoritma Apriori yang menghasilkan interesting rule yang akan dijadikan pola frekuensi yang kemudian diterjemahkan ke dalam bentuk pengetahun. Sedangkan pada penelitian ini, algoritma yang digunakan adalah Algoritma FP-Growth, dimana algoritma ini akan menghasilkan pohon yaitu FP-Tree yang menggambarkan frekuensi dari masingmasing item dari semua transaksi, sehingga pola frekuensi yang dihasilkan lebih jelas dan lebih mudah untuk diterjemahkan ke dalam bentuk pengetahuan. Penelitian [17] sudah menerapkan algoritma FP-Growth untuk membuat sebuah keputusan dalam merekomendasikan menu paket makanan yang akan dipilih oleh pelanggan pada restoran seafood XYZ. Restoran ini memerlukan solusi untuk kebijakan bisnisnya dalam merekomendasikan menu paket makanan yang ada pada restoran tersebut. Solusi yang dibutuhkan pihak restoran adalah bagaimana caranya agar bisa menentukan pola frekuensi dari pembelian makanan, sehingga menu paket makanan yang ditawarkan dapat dibeli oleh pelanggan.

Kemudian pada penelitian [18], algoritma FP-Growth juga digunakan untuk mengetahui pola pembelian pelanggan pada sebuah kafe yaitu Corm Cafe. Pola pembelian yang akan diketahui yaitu pola pembelian makanan dan minuman yang ada di kafe tersebut dimana akan digunakan untuk inventaris dan strategi bisnis.

\section{METODOLOGI PENELITIAN}

Penelitian ini dilakukan di Rumah Makan yang dikelola oleh perantau Minang di Singkawang, Kalimantan Barat. Rumah makan ini bernama Takana Juo yang menjual berbagai jenis lauk masakan Padang yang memiliki cita rasa yang khas.. Penelitian dilakukan sesuai dengan tahapan penelitian yang sudah ditetapkan sebelumnya. Tahapan penelitian dapat dilihat pada Gambar 1.

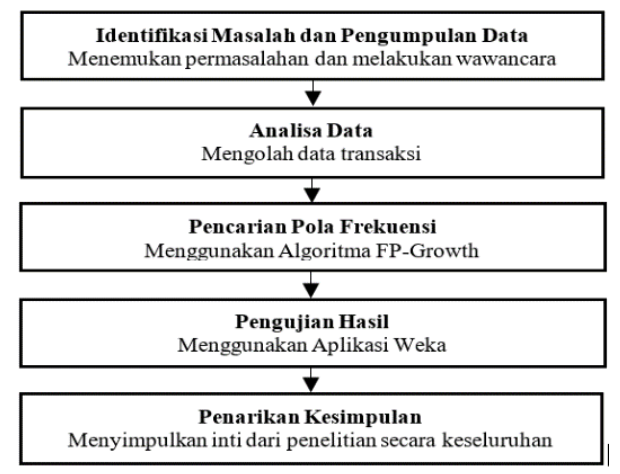

Gambar 1. Tahapan Penelitian 
Gambar 1 diatas menggambarkan beberapa langkah yang dilakukan dalam penelitian ini yang dimulai dari proses identifikasi masalah yang terdapat pada Rumah Makan Takana Juo sampai dengan penarikan kesimpulan dari keseluruhan penelitian ini.

Proses identifikasi masalah dan pengumpulan data dimulai dengan menghubungi pemilik Rumah Makan Takana Juo melalui sambungan telepon. Kemudian melakukan wawancara dengan pemilik melalui panggilan video. Data diberikan oleh pemilik rumah makan berupa data transaksi pelanggan yang makan di tempat, yaitu pelanggan yang makan dengan cara dihidang. Pada saat wawancara ini diperoleh masalah yang terjadi di Rumah Makan Takana Juo. Masalah yang muncul adalah adanya lauk yang lebih cepat habis dan ada lauk yang tersisa setiap harinya, sehingga rumah makan rugi, karena lauk yang tidak habis tidak bisa dijual lagi keesokan harinya. Agar dapat membantu pemilik rumah makan dalam mengatasi masalah tersebut, maka diminta data transaksi penjualan yang terdapat disana. Kemudian data penjualan tersebut dikirimkan melalui email oleh pemilik rumah makan.

Setelah data diperoleh, dilakukan proses analisa data. Data yang diolah yaitu data transaksi penjualan yang pembelian lauknya diatas 3 jenis dalam satu transaksi. Hal ini dilakukan agar dapat melihat bagaimana pelanggan dalam membeli lauk. Jika menggunakan data satu lauk per satu transaksi, pola beli konsumen tidak akan bisa diperoleh. Setelah data selesai diolah, maka dilakukan proses pencarian pola frekuensi dengan menggunakan algoritma FP-Growth, yang menghasilkan FP-Tree dan interesting rules (strong association rules) sehingga akan ditemukan kombinasi antar lauk dari rumah makan tersebut. Kemudian dilakukan pengujian dengan menggunakan perangkat lunak analisis data yaitu Weka 3.8.3.

\section{HASIL DAN PEMBAHASAN}

\subsection{Hasil Penelitian}

Tujuan dilakukan penelitian ini adalah untuk membantu menganalisis data transaksi penjualan yang ada pada Rumah Makan Takana Juo, agar pemilik rumah makan dapat melihat dan mempelajari pola beli pelanggan dalam membeli lauk, sehingga tidak terjadi masalah banyaknya sisa lauk pada hari ini yang tidak bisa dijual lagi keesokan harinya. Penelitian ini menggunakan metode asosiasi untuk mendapatkan kombinasi antar lauk yang dibeli oleh pelanggan menggunakan algoritma FP-Growth.

Data yang dipakai dalam penelitian ini adalah data transaksi penjualan lauk masakan padang yang ada pada Rumah Makan Takana Juo. Data transaksi penjualan tersebut diberikan oleh pemilik rumah makan tersebut. Data yang digunakan adalah data transkasi penjualan lauk sebanyak 12 transaksi yang merupakan hasil filter dari total transaksi selama satu bulan. Data transaksi penjualan yang digunakan hanya transaksi yang pembeliannya 3 jenis lauk atau lebih, sehingga akan dihasikan pola frekuensi penjualan lauk. Dari 12 data transaksi yang digunakan, terdapat 20 lauk yang berbeda yang dapat dilihat pada Tabel 1.

Tabel 1. Daftar Lauk Dalam Transaksi

\begin{tabular}{clc}
\hline No & \multicolumn{1}{c}{ Nama Lauk } & Kode \\
\hline 1 & Asam Padeh Dagiang & APD \\
2 & Asam Padeh Ikan & API \\
3 & Ayam Bakar & AB \\
4 & Ayam Goreng Bumbu & AGB \\
5 & Ayam Gulai & AG \\
6 & Ayam Kecap & AK \\
7 & Dendeng Kariang & DK \\
8 & Dendeng Lambok & DL \\
9 & Gulai Kikil & GK \\
10 & Gulai Talua & GT \\
11 & Gulai Usus & GU \\
12 & Ikan Bakar & IB \\
13 & Ikan Goreng & IG \\
14 & Ikan Goreng Lado Merah & IGL \\
15 & Ikan Gulai Toco & IGT \\
16 & Palai Bada & PB \\
17 & Randang Ayam & RA \\
18 & Randang Daging & RD \\
19 & Sop Tulang & ST \\
20 & Talua Dadar & TD \\
\hline
\end{tabular}

Tabel 1 mendefinisikan daftar lauk masakan padang dari semua transaksi yang akan dioleh pada penelitian ini. Data semua transaksi penjualan yang akan diolah dapat dilihat padang Tabel 2

Tabel 2. Data Transaksi Penjualan Lauk 
1 Dendeng Lambok, Ayam Gulai, Randang Ayam, Ayam Kecap, Randang Dagiang, Dendeng Kariang, Ayam Bakar, Ayam Goreng Bumbu, Ikan Goreng Lado Merah

Ikan Gulai Toco, Dendeng Lambok, Ayam Bakar, Ikan Goreng, Dendeng Kariang, Randang Dagiang, Asam Padeh Dagiang

3 Randang Dagiang, Ayam Bakar, Asam Padeh Ikan, Dendeng Lambok, Gulai Usus, Ikan Goreng, Gulai Kikil

$4 \quad$ Gulai Talua, Palai Bada, Sop Tulang, Ikan Bakar, Dendeng Lambok, Randang Ayam, Ayam Bakar

$5 \quad$ Asam Padeh Dagiang, Ikan Gulai Toco, Dendeng Lambok, Ayam Bakar, Ikan Goreng

6 Asam Padeh Ikan, Ayam Bakar, Dendeng Lambok, Gulai Usus, Ikan Goreng, Gulai Kikil

7 Talua Dadar, Ayam Kecap, Randang Dagiang, Ayam Bakar, Ayam Goreng Bumbu, Ikan Goreng Lado Merah, Ikan Bakar

$8 \quad$ Ayam Bakar, Randang Ayam, Talua Dadar, Ayam Kecap, Randang Dagiang, Dendeng Kariang

9 Ayam Bakar, Randang Dagiang, Talua Dadar, Ikan Bakar

10 Ayam Bakar, Ayam Goreng Bumbu, Ikan Goreng Lado Merah, Ayam Gulai, Ikan Gulai Toco

11 Ayam Bakar, Ayam Goreng Bumbu, Ikan Goreng Lado Merah, Ikan Gulai Toco

12 Ikan Bakar, Ayam Bakar, Ayam Goreng Bumbu, Ayam Gulai, Dendeng Kariang

Tabel 2 menampilkan semua transaksi penjualan lauk yang akan diolah yaitu sebanyak 12 data transaksi. Semua data transaksi penjualan yang digunakan adalah transaksi yang memiliki 3 jenis lauk untuk satu transaksi. Kemudian, dilakukan proses penghitungan banyak support dari masing-masing lauk dari semua transaksi penjualan yang terjadi. Banyak support dari masing-masing lauk, dapat dilihat pada Tabel 3

Tabel 3. Support Masing-Masing Lauk

\begin{tabular}{clc}
\hline No & \multicolumn{1}{c}{ Nama Lauk } & Frekuensi \\
\hline 1 & Asam Padeh Dagiang & 2 \\
2 & Asam Padeh Ikan & 2 \\
3 & Ayam Bakar & 12 \\
4 & Ayam Goreng Bumbu & 5 \\
5 & Ayam Gulai & 3 \\
6 & Ayam Kecap & 3 \\
7 & Dendeng Kariang & 4 \\
8 & Dendeng Lambok & 6 \\
9 & Gulai Kikil & 2 \\
10 & Gulai Talua & 1 \\
11 & Gulai Usus & 2 \\
12 & Ikan Bakar & 4 \\
13 & Ikan Goreng & 4 \\
14 & Ikan Goreng Lado Merah & 4 \\
15 & Ikan Gulai Toco & 4 \\
16 & Palai Bada & 1 \\
17 & Randang Ayam & 3 \\
18 & Randang Daging & 6 \\
19 & Sop Tulang & 1 \\
20 & Talua Dadar & 3 \\
\hline
\end{tabular}

Tabel 3 memperlihatkan banyaknya lauk yang dibeli dari total 12 transaksi penjulan. Ditandai dengan nilai support dari masing-masing lauk. Untuk mendapatkan pola frekuensi penjualan lauk maka harus ditentukan terlebih dahulu nilai minimum support. Penelitian ini menggunakan nilai minimum support yaitu paling sedikit 1 item barang dibeli sebanyak 4 kali atau 33,33\% dari total 12 transaksi. Nilai support Ayam Bakar diperoleh dari jumlah frekuensi Ayam Bakar dibagi total transaksi.

$$
\text { Support }(\text { Ayam Bakar })=\frac{\text { Jumlah Transaksi Ayam Bakar }}{\text { Total transaksi Penjualan }}=\frac{12}{12}=1=100 \%
$$

Sehingga lauk yang akan dibuat pola frekuensinya akan berkurang seperti terlihat pada Tabel 4 .

Tabel 4. Lauk Dengan Minimum Support 4

\begin{tabular}{lcc}
\hline \multicolumn{1}{c}{ Kode } & Frekuensi & Support \\
\hline Ayam Bakar & 12 & $100,00 \%$ \\
Dendeng Lambok & 6 & $50,00 \%$ \\
Randang Daging & 6 & $50,00 \%$ \\
Ayam Goreng Bumbu & 5 & $41,67 \%$ \\
Dendeng Kariang & 4 & $33,33 \%$ \\
Ikan Bakar & 4 & $33,33 \%$ \\
Ikan Goreng & 4 & $33,33 \%$ \\
Ikan Goreng Lado Merah & 4 & $33,33 \%$ \\
Ikan Gulai Toco & 4 & $33,33 \%$ \\
\hline
\end{tabular}


Tabel 4 menunjukkan lauk yang mempunya nilai minimum support yaitu 4 sebanyak 9 item dimana item ini yang akan dicari pola frekuensi penjualannya. Selanjutnya, setiap transaksi akan diurut semua itemnya dari nilai support terbesar ke nilai support terkecil seperti ditunjukkan pada Tabel 5.

Tabel 5. Item Transaksi Setelah Diurutkan

\begin{tabular}{|c|c|}
\hline Trans & Item \\
\hline 1 & $\begin{array}{l}\text { Ayam Bakar, Dendeng Lambok, Randang Dagiang, Ayam Goreng Bumbu, Dendeng Kariang, Ikan Goreng Lado } \\
\text { Merah, Ayam Gulai, Ayam Kecap, Randang Ayam }\end{array}$ \\
\hline 2 & $\begin{array}{l}\text { Ayam Bakar, Dendeng Lambok, Randang Dagiang, Dendeng Kariang, Ikan Goreng, Ikan Gulai Toco, Asam } \\
\text { Padeh Dagiang }\end{array}$ \\
\hline 3 & Ayam Bakar, Dendeng Lambok, Randang Dagiang, Ikan Goreng, Asam Padeh Ikan, Gulai Kikil, Gulai Usus \\
\hline 4 & Ayam Bakar, Dendeng Lambok, Ikan Bakar, Randang Ayam, Gulai Talua, Palai Bada, Sop Tulang \\
\hline 5 & Ayam Bakar, Dendeng Lambok, Ikan Goreng, Ikan Gulai Toco, Asam Padeh Dagiang \\
\hline 6 & Ayam Bakar, Dendeng Lambok, Ikan Goreng, Asam Padeh Ikan, Gulai Kikil, Gulai Usus \\
\hline 7 & $\begin{array}{l}\text { Ayam Bakar, Randang Dagiang, Ayam Goreng Bumbu, Ikan Bakar, Ikan Goreng Lado Merah, Ayak Kecap, } \\
\text { Talua Dadar }\end{array}$ \\
\hline 8 & Ayam Bakar, Randang Dagiang, Dendeng Kariang, Ayam Kecap, Randang Ayam, Talua Dadar \\
\hline 9 & Ayam Bakar, Randang Dagiang, Ikan Bakar, Talua Dadar \\
\hline 10 & Ayam Bakar, Ayam Goreng Bumbu, Ikan Goreng Lado Merah, Ikan Gulai Toco, Ayam Gulai \\
\hline 11 & Ayam Bakar, Ayam Goreng Bumbu, Ikan Goreng Lado Merah, Ikan Gulai Toco \\
\hline 12 & Ayam Bakar, Ayam Goreng Bumbu, Dendeng Kariang, Ikan Bakar, Ayam Gulai \\
\hline
\end{tabular}

Pada Tabel 5 terlihat pada setiap transaksi bahwa lauk telah diurut sesuai dengan frekuensi kemunculan dari masingmasing lauk. Selanjutnya dapat dibuat frekuensi pohon yang disebut dengan FP-Tree (Frequent-Pattern Tree) yang terlihat pada Gambar 2.

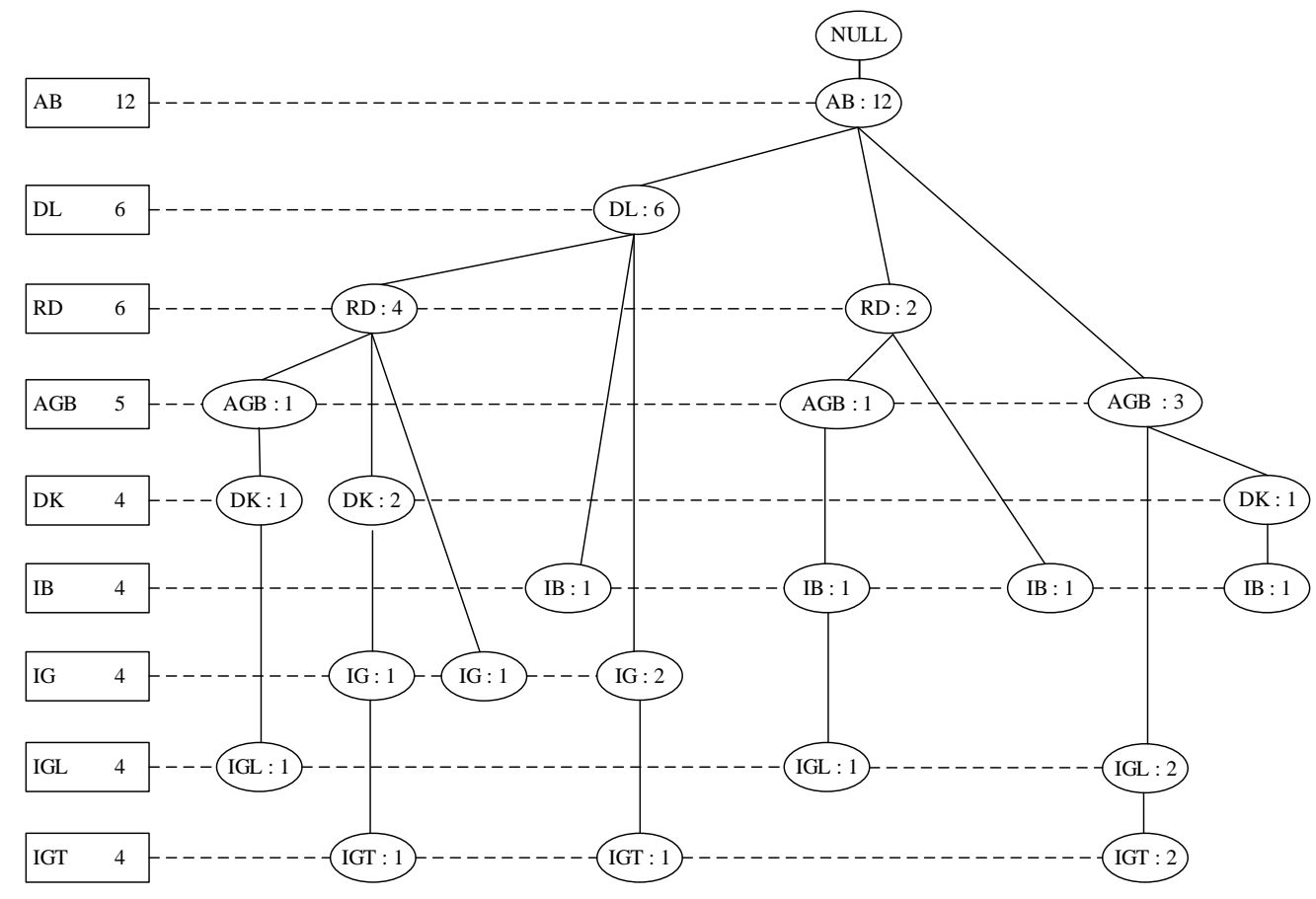

Gambar 2. FP-Tree Dari Semua Transaksi

Gambar 2 menggambarkan bentuk pohon pola frekuensi dari 12 transaksi yang digunakan pada penelitian ini. Tampak bahwa lauk AB (Ayam Bakar) merupakan lauk yang paling sering muncul dari semua transaksi. Gambar 2 digunakan untuk membuat kondisi pola frekuensi dari masing-masing lauk yang dibeli oleh pelanggan. FP-Tree menunjukkan frekuensi kemunculan lauk yang dibeli oleh pelanggan. Setelah FP-Tree diperoleh, langkah selanjutnya adalah menentukan conditional pattern base dari semua lauk yang memiliki frekuensi sama atau lebih besar dari minimum support seperti yang terlihat pada Tabel 6.

Tabel 6. Conditional Pattern Base

\begin{tabular}{ll}
\hline \multicolumn{1}{c}{ Item } & \multicolumn{1}{c}{ Conditional Pattern Base } \\
\hline Ikan Gulai Toco & \{Ayam Bakar, Dendeng Lambok, Randang Dagiang, Dendeng Kariang, Ikan Goreng : 1, \\
& \{Ayam Bakar, Dendeng Lambok, Ikan Goreng : 1\}, \\
& \{Ayam Bakar, Ayam Goreng Bumbu, Ikan Goreng Lado Merah : 2 $\}$ \\
Ikan Goreng Lado & \{Ayam Bakar, Dendeng Lambok, Randang Dagiang, Ayam Goreng Bumbu, Dendeng Kariang : 1\}, \\
Merah & \{Ayam Bakar, Randang Dagiang, Ayam Goreng Bumbu, Ikan Bakar : 1\},
\end{tabular}




\begin{tabular}{|c|c|}
\hline Item & $\begin{aligned} \text { Conditional Pattern Base } \\
\end{aligned}$ \\
\hline & $\{$ Ayam Bakar, Ayam Goreng Bumbu : 2\} \\
\hline Ikan Goreng & $\begin{array}{l}\text { \{Ayam Bakar, Dendeng Lambok, Randang Dagiang, Dendeng Kariang : } 1\}, \\
\{\text { Ayam Bakar, Dendeng Lambok, Randang Dagiang : } 1\},\end{array}$ \\
\hline & $\{$ Ayam Bakar, Dendeng Lambok : 2$\}$ \\
\hline Ikan Bakar & $\{$ Ayam Bakar, Dendeng Lambok : 1$\}$ \\
\hline & \{Ayam Bakar, Randang Dagiang, Ayam Goreng Bumbu : 1\}, \\
\hline & $\{$ Ayam Bakar, Ayam Goreng Bumbu, Dendeng Kariang : 1 \} \\
\hline Dendeng Kariang & $\begin{array}{l}\text { \{Ayam Bakar, Dendeng Lambok, Randang Dagiang, Ayam Goreng Bumbu : } 1\} \text {, } \\
\text { \{Ayam Bakar, Dendeng Lambok, Randang Dagiang : } 2\}, \\
\{\text { Ayam Bakar, Ayam Goreng Bumbu : } 1\}\end{array}$ \\
\hline Ayam Goreng & $\{$ Ayam Bakar, Dendeng Lambok, Randang Dagiang : 1\}, \\
\hline Bumbu & $\begin{array}{l}\{\text { Ayam Bakar, Randang Dagiang : } 1\} \\
\{\text { Ayam Bakar : } 3\}\end{array}$ \\
\hline Randang Dagiang & $\begin{array}{l}\{\text { Ayam Bakar, Dendeng Lambok : } 4\}, \\
\{\text { Ayam Bakar : } 2\}\end{array}$ \\
\hline Dendeng Lambok & $\{$ Ayam Bakar : 6$\}$ \\
\hline Ayam Bakar & $\begin{array}{l}\text { \{Ayam Bakar, Dendeng Lambok, Randang Dagiang, Dendeng Kariang, Ikan Goreng : } 1\} \text {, } \\
\text { \{Ayam Bakar, Dendeng Lambok, Ikan Goreng: } 1\}, \\
\{\text { Ayam Bakar, Ayam Goreng Bumbu, Ikan Goreng Lado Merah : } 2\}\end{array}$ \\
\hline
\end{tabular}

Tabel 6 merupakan hasil dari proses penentuan conditional pattern base dari semua lauk yang nilai frekuensi sama atau lebih besar dari minimum support. Selanjutnya ditentukan conditional FP-Tree yang diperoleh dari FP-Tree diatas. Conditional FP-Tree dapat dilihat pada Tabel 7.

Tabel 7. Conditional FP-Tree

\begin{tabular}{|c|c|}
\hline Item & Conditional FP-Tree $>=$ Min Support \\
\hline Ikan Gulai Toco & $\{$ Ayam Bakar : 4$\}$ \\
\hline Ikan Goreng Lado Merah & $\{$ Ayam Bakar : 4\}, \{Ayam Goreng Bumbu : 4\} \\
\hline Ikan Goreng & $\{$ Ayam Bakar : 4$\},\{$ Dendeng Lambok : 4$\}$ \\
\hline Ikan Bakar & $\{$ Ayam Bakar : 4$\}$ \\
\hline Dendeng Kariang & $\{$ Ayam Bakar : 4$\}$ \\
\hline Ayam Goreng Bumbu & $\{$ Ayam Bakar : 5$\}$ \\
\hline Randang Dagiang & $\{$ Ayam Bakar : 6$\}$ \\
\hline Dendeng Lambok & $\{$ Ayam Bakar : 6$\}$ \\
\hline Ayam Bakar & $\{$ Ayam Bakar : 4$\}$ \\
\hline
\end{tabular}

Tabel 7 adalah hasil Conditional FP-Tree dengan nilai lebih besar atau sama dengan minimum support. Tahapan selanjutnya adalah mencari Frequent Itemset yaitu mencari single path yang kemudian dikombinasikan dengan item pada Conditional FP-Tree yang dapat dilihat pada Tabel 8

Tabel 8. Frequent Itemset

\begin{tabular}{|c|c|}
\hline Item & Frequent Itemset \\
\hline Ikan Gulai Toco & $($ Ayam Bakar $\rightarrow$ Ikan Gulai Toco $: 4)$ \\
\hline \multirow[t]{3}{*}{ Ikan Goreng Lado Merah } & (Ayam Bakar $\rightarrow$ Ikan Goreng Lado Merah : 4), \\
\hline & (Ayam Goreng Bumbu $\rightarrow$ Ikan Goreng Lado Merah : 4), \\
\hline & (Ayam Bakar, Ayam Goreng Bumbu $\rightarrow$ Ikan Goreng Lado Merah : 4) \\
\hline \multirow[t]{3}{*}{ Ikan Goreng } & (Ayam Bakar $\rightarrow$ Ikan Goreng : 4), \\
\hline & (Dendeng Lambok $\rightarrow$ Ikan Goreng : 4), \\
\hline & (Ayam Bakar, Dendeng Lambok $\rightarrow$ Ikan Goreng : 4) \\
\hline Ikan Bakar & $($ Ayam Bakar $\rightarrow$ Ikan Bakar : 4) \\
\hline Dendeng Kariang & $($ Ayam Bakar $\rightarrow$ Dendeng Kariang : 4) \\
\hline Ayam Goreng Bumbu & $($ Ayam Bakar $\rightarrow$ Ayam Goreng Bumbu : 5) \\
\hline Randang Dagiang & (Ayam Bakar $\rightarrow$ Randang Dagiang : 6) \\
\hline Dendeng Lambok & $($ Ayam Bakar $\rightarrow$ Dendeng Lambok : 6) \\
\hline Ayam Bakar & $($ Ayam Bakar $\rightarrow$ Ikan Gulai Toco $: 4)$ \\
\hline
\end{tabular}

Dari frequent itemset yang ditemukan pada Tabel 8, maka dapat dihitung nilai confidence.

Confidence(Ayam Bakar, Ikan Gulai Toco)

$=\frac{\text { Trans Ayam Bakar dan Ikan Gulai Toco }}{\text { Total trans Ayam Bakar }}=\frac{4}{12}=0,33=33,33 \%$

Nilai support dan nilai confidence dari semua frequent itemset yang dapat dilihat pada Tabel 9 
JURNAL MEDIA INFORMATIKA BUDIDARMA

Volume 5, Nomor 1, Januari 2021, Page 242-250

ISSN 2614-5278 (media cetak), ISSN 2548-8368 (media online)

Available Online at https://ejurnal.stmik-budidarma.ac.id/index.php/mib

DOI 10.30865/mib.v5i1.2643

Tabel 9. Nilai Support Dan Confidence

\begin{tabular}{lllc}
\hline \multicolumn{1}{c}{ Jika Membeli } & \multicolumn{1}{c}{ Maka Membeli } & Support & Confidence \\
\hline Ayam Bakar & Ikan Gula Toco & $33,33 \%$ & $33,33 \%$ \\
Ayam Bakar & Ikan Goreng Lado Merah & $33,33 \%$ & $33,33 \%$ \\
Ayam Goreng Bumbu & Ikan Goreng Lado Merah & $33,33 \%$ & $80,00 \%$ \\
Ayam Bakar, Ayam Goreng Bumbu & Ikan Goreng Lado Merah & $33,33 \%$ & $80,00 \%$ \\
Ayam Bakar & Ikan Goreng & $33,33 \%$ & $33,33 \%$ \\
Dendeng Lambok & Ikan Goreng & $33,33 \%$ & $66,67 \%$ \\
Ayam Bakar, Dendeng Lambok & Ikan Goreng & $33,33 \%$ & $66,67 \%$ \\
Ayam Bakar & Ikan Bakar & $33,33 \%$ & $33,33 \%$ \\
Ayam Bakar & Dendeng Kariang & $33,33 \%$ & $33,33 \%$ \\
Ayam Bakar & Ayam Goreng Bumbu & $41,67 \%$ & $41,67 \%$ \\
Ayam Bakar & Randang Dagiang & $50,00 \%$ & $50,00 \%$ \\
Ayam Bakar & Dendeng Lambok & $50,00 \%$ & $50,00 \%$ \\
\hline
\end{tabular}

Setelah mendapatkan nilai support dan nilai confidence pada Tabel 9, maka selanjutnya adalah menetukan interesting rules (strong association rules). Untuk mendapatkannya, maka harus ditentukan terlebih dahulu minimum confidence. Jika nilai minimum confidence ditentukan $50 \%$, maka interesting rules yang diperoleh terlihat pada Tabel 10

Tabel 10. Interesting Rules

\begin{tabular}{lcc}
\hline \multicolumn{1}{c}{ Interesting Rules } & Support & Confidence \\
\hline Jika membeli Ayam Goreng Bumbu maka juga membeli Ikan Goreng Lado Merah & $33,33 \%$ & $80,00 \%$ \\
Jika membeli Ayam Bakar dan Ayam Goreng Bumbu maka juga membeli Ikan Goreng Lado Merah & $33,33 \%$ & $80,00 \%$ \\
Jika membeli Dendeng Lambok maka juga membeli Ikan Goreng & $33,33 \%$ & $66,67 \%$ \\
Jika membeli Ayam Bakar dan Dendeng Lambok maka juga membeli Ikan Goreng & $33,33 \%$ & $66,67 \%$ \\
Jika membeli Ayam Bakar maka juga membeli Randang Dagiang & $50,00 \%$ & $50,00 \%$ \\
Jika membeli Ayam Bakar maka juga membeli Dendeng Lambok & $50,00 \%$ & $50,00 \%$ \\
\hline
\end{tabular}

Tabel 10 diatas menampilkan interesting rule yang memenuhi minimum support yaitu 33,33\% dan minimum confidence yaitu $50 \%$ sebanyak 6 interesting rule.

\subsection{Pengujian Hasil}

Pengujian hasil analisis dilakukan dengan menggunakan perangkat lunak analisis data mining yaitu Weka 3.8.3. Pada saat Weka mulai dijalankan, halaman pertama yang muncul terlihat pada Gambar 3.

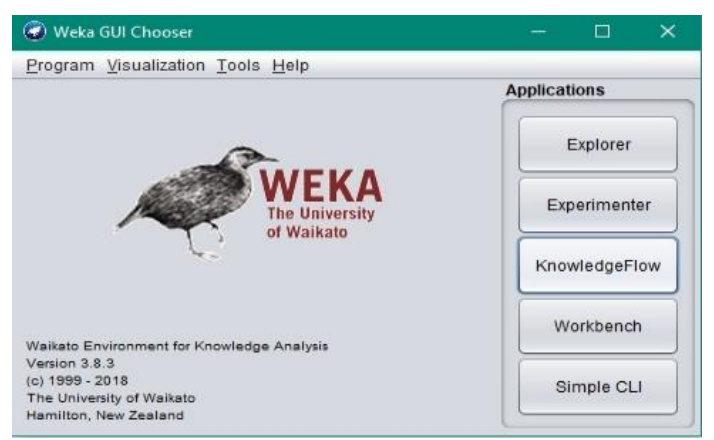

Gambar 3. Weka GUI Chooser

Gambar 3 adalah halaman yang pertama muncul ketika Weka dijalankan. Ada beberapa tombol yang bisa dipilih untuk melakukan analisis. Pada penelitian ini, tombol KnowledgeFlow yang akan digunakan. Jika tombol ini ditekan, maka akan muncul form seperti Gambar 4.

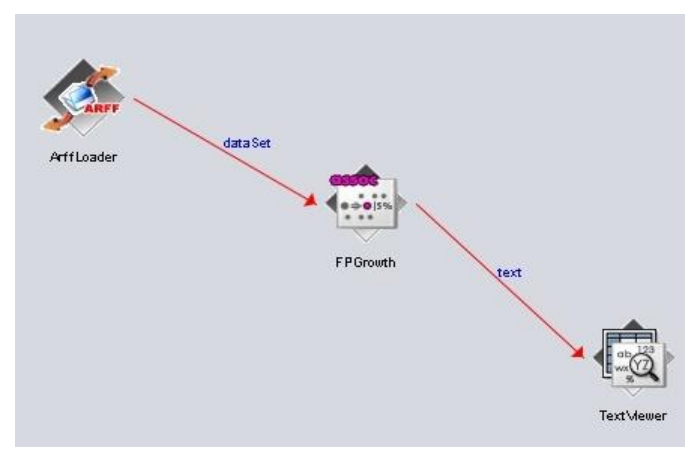

Gambar 4. Weka Knowledgeflow Environment

Dewi Eka Putri, Copyright (C2021, MIB, Page 248 
Gambar 4 merupakan form untuk melakukan analisis pengetahuan. Langkah pertama dimulai dengan menekan ArffLoader untuk memanggil data yang akan diproses. Data yang digunakan menggunakan format file *.arff. Langkah kedua adalah memilih algoritma yang digunakan yaitu FPGrowth. Kemudian dilakukan Running Process. Hasilnya akan ditampilkan dalam TextViewer seperti Gambar 5

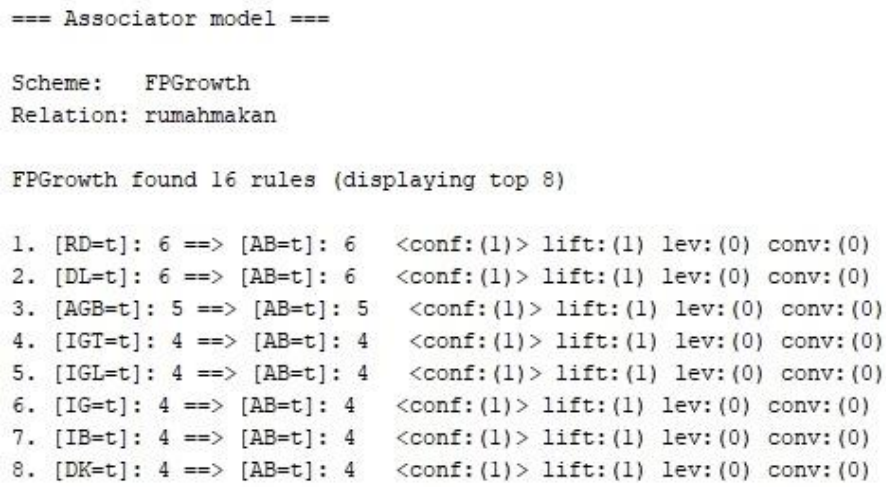

Gambar 5. Weka Text Viewer

Gambar 5 menampilkan hasil proses yang dilakukan oleh FP-Growth dalam perangkat lunak Weka. Hasil ini sama dengan proses manual yang dilakukan sebelumnya dalam mengurutkan frekuensi barang yang lebih besar atau sama dengan minimum support.

\section{KESIMPULAN}

Setelah penelitian ini selesai dilakukan, maka terdapat kesimpulan yang bisa dikemukakan. Kesimpulan yang bisa diambil dari penelitian ini adalah penerapan Algoritma FP-Growth di Rumah Makan Takana Juo dalam melihat pola penjualan lauk masakan Padang yaitu kecenderungan lauk yang terjual di Rumah Makan Takana Juo, salah satu contoh pola penjualan lauk yang dihasilkan adalah dari 12 transaksi yang membeli Ayam Bakar, 50\% (6 transaksi) membeli Dendeng Lambok. Hasil dari penelitian ini adalah bagaimana pemilik rumah makan dapat mengambil keputusan dalam pengadaan lauk yang dilihat dari pola frekuensi pembelian lauk yang dilakukan oleh pelanggan. Penelitian ini dapat membantu pemilik rumah makan dalam memecahkan masalah dengan melihat kecenderungan lauk yang dibeli secara bersamaan oleh pelanggan, sehingga akan memudahkan pemilik rumah makan dalam mengatur pengadaan lauk yang akan dijual. Penelitian ini juga masih memiliki kekurangan, diharapkan ada penelitian lanjutan untuk memperdalam metode dan algoritma ini atau menggunakan metode data mining lain yang lebih cocok digunakan dalam menemukan pola frekuensi penjualan lauk.

\section{REFERENCES}

[1] A. Herdiansah, Y. Sugiyani, and R. S. Septarini, "Penerapan Pembelajaran E-Bisnis Siswa Pkbm Paja Mandiri Pada Pembuatan Prototipe Sistem Rumah Makan Masakan Padang Kutabumi," JIKA (Jurnal Inform., vol. 4, no. 2, p. 39, 2020.

[2] E. Yulianti and F. Juwita, "Sistem Pendukung Keputusan Pemilihan Tempat Kuliner di Kota Padang Menggunakan Metode Perbandingan Eksponensial (MPE)," J. TEKNOIF, vol. 4, no. 2, pp. 51-58, 2016

[3] I. D. P. Wijana, "Bahasa Dan Etnisitas: Studi Tentang Nama-Nama Rumah Makan Padang," Linguist. Indones., vol. 34 no. 2, pp. 195-206, 2016.

[4] Y. Wardi, A. Abror, and O. Trinanda, "Service Excellent Rumah Makan Padang Dalam Perspektif Wisata Islami," Int. J. Community Serv. Learn., vol. 3, no. 3, pp. 133-137, 2019.

[5] Nelisa and A. Fitrul Hadi, "Perancangan Aplikasi Data Mining Transaksi Penjualan Untuk Mengetahui Pola Beli Konsumen Pada Toko Singgalang Padang Menggunakan Algoritma Apriori Berbasis Web," Maj. Ilm., vol. 25, no. 1, pp. $37-44,2018$

[6] A. Wanto et al., Data Mining: Algoritma dan Implementasi. Yayasan Kita Menulis, 2020

[7] P. SWARA and T. I. M. A. CATERING, MASAKAN PADANG PALING LAMAK. Puspa Swara, 2014.

[8] P. SWARA and Y. L. ENDRO, MASAKAN PADANG ALA RESTO TERLENGKAP. Puspa Swara, 2014.

[9] E. P. W. Mandala, "POLA FREKUENSI JUDUL SKRIPSI MAHASISWA TEKNIK INFORMATIKA DENGAN ALGORITMA APRIORI," J. TeknoIf, vol. 5, no. 2, Oct. 2017.

[10] Maharani et al., "IMPLEMENTASI DATA MINING UNTUK PENGATURAN LAYOUT MINIMARKET DENGAN MENERAPKAN ASSOCIATION RULE," vol. 4, no. 4, pp. 6-11, 2017.

[11] D. E. Putri, "Pola Frekuensi Penjualan Barang Bali Mart Menggunakan Fp-Growth," JOISIE (Journal Inf. Syst. Informatics Eng., vol. 4, no. 1, p. 15, 2020.

[12] A. Maulana and A. A. Fajrin, "Penerapan Data Mining Untuk Analisis Pola Pembelian Konsumen dengan Algoritma FPGrowth pada Data Transaksi Penjualan Spare Part Motor," KLIK-KUMPULAN J. ILMU Komput., vol. 5, no. 1, pp. 27 36,2018

[13] H. E. Simanjuntak and W. Windarto, "Analisa Data Mining Menggunakan Frequent Pattern Growth pada Data Transaksi Penjualan PT Mora Telematika Indonesia untuk Rekomendasi Strategi Pemasaran Produk Internet," J. Media Inform. Budidarma, vol. 4, pp. 914-923, 2020. 
JURNAL MEDIA INFORMATIKA BUDIDARMA

Volume 5, Nomor 1, Januari 2021, Page 242-250

ISSN 2614-5278 (media cetak), ISSN 2548-8368 (media online)

Available Online at https://ejurnal.stmik-budidarma.ac.id/index.php/mib

DOI 10.30865/mib.v5i1.2643

[14] O. Zakaria and K. Kusrini, "IMPLEMENTASI DATA MINING TERHADAP PENYUSUNAN LAYOUT MAKANAN PADA RUMAH MAKAN PADANG 'MURAH MERIAH,”, SEMNASTEKNOMEDIA ONLINE, vol. 1, no. 1, pp. 1-7, 2013.

[15] D. Sophia and L. Y. Banowosari, "Implementasi Metode Aturan Asosiasi Menggunakan Algoritma Apriori Pada Data Transaksi Penjualan Di Waroeng Spesial Sambal,” J. Inform. dan Komput., vol. 22, no. 1, pp. 44-56, 2017.

[16] A. B. Kusdinar, D. Riyadi, and A. Asriyanik, "Implementasi Algoritma Apriori Pada Penyusunan Menu Makanan Rumah Makan Prasmanan,” J. Tek. Inform. dan Sist. Inf., vol. 6, no. 2, pp. 391-399, 2020.

[17] P. Lintang, M. Iqbal, and A. Pujianto, "Sistem Rekomendasi Paket Makanan Dengan Algoritma FP-Growth Pada Restoran Seafood XYZ," Semnasteknomedia Online, pp. 127-132, 2017.

[18] N. Isa, N. A. Kamaruzzaman, M. A. Ramlan, N. Mohamed, and M. Puteh, "Market Basket Analysis of Customer Buying Patterns at Corm Café,” Int. J. Eng. Technol., vol. 7, no. October, pp. 119-123, 2018. 